\title{
Media Pembelajaran Berbasis Powerpoin Untuk Memfasilitasi Perilaku Keselamatan Anak Usia 5-6 Tahun
}

\author{
Devita Savitri \\ Universitas Pendidikan Indonesia \\ Email: devita@upi.edu \\ Badru Zaman \\ Universitas Pendidikan Indonesia \\ Email: badruzaman@upi.edu
}

Article received: 27 Agustus 2020, Review process: 15 Februari 202021,
Article Accepted: 30 Maret 2021, Article published: 30 Maret 2021

\begin{abstract}
The purpose of this study is to describe the basis of product requirements, product design, product testing process and product end results. This study uses the method Design Based Research (DBR) developed by Reeves. Data collection was carried out with observation techniques, expert judgment, interviews, and study documentation. Validation is carried out by media experts, and pedagogic experts, who will later be revised according to the advice of the validator until the product is said to be feasible. In general, this Powerpoint based learning media is suitable for use in learning. Reflection on the development of this product is to produce Powerpoint based learning media for the safety behavior pedestrian of children aged 5-6 years. This study produced Powerpoint based learning media files for the safety behavior pedestrian of 5-6 year olds in the form of Compact Disks (CD), and Powerpoint based learning media guidebooks for the safety behavior pedestrian of children aged 5-6 years.
\end{abstract}

Keywords: media learning, Powerpoint, safety behavior, early childhood

\begin{abstract}
Abstrak
Tujuan dari penelitian ini yaitu mendeskripsikan dasar kebutuhan produk, rancangan produk, proses uji coba produk dan hasil akhir produk. Penelitian ini menggunakan metode Design Based Research (DBR) yang dikembangkan oleh Reeves. Pengumpulan data dilakukan dengan teknik observasi, expert judgement, wawancara, dan studi dokumentasi. Validasi dilakukan oleh ahli media, dan ahli pedagogik, yang nantinya akan dilakukan revisi sesuai saran dari validator sampai produk dikatakan layak. Secara umum, media pembelajaran berbasis Powerpoint ini layak digunakan dalam pembelajaran. Refleksi pengembangan produk ini yakni menghasilkan media pembelajaran berbasis Powerpoint untuk memfasilitasi perilaku keselamatan pejalan kaki anak usia 5-6 tahun. Penelitian ini menghasilkan file media pembelajaran berbasis Powerpoint untuk memfasilitasi perilaku keselamatan pejalan kaki anak usia 5-6 tahun dalam bentuk Compact
\end{abstract}


Disk (CD), dan buku panduan media pembelajaran berbasis Powerpoint untukmemfasilitasi perilaku keselamatan anak usia 5-6 tahun.

Kata Kunci: media pembelajaran, Powerpoint, perilaku keselamatan, anak usia dini

\section{PENDAHULUAN}

Pada penelitian NCSA (2010) Setiap tahun di Amerika Serikat, sekitar 25.000 anak-anak berusia 0 sampai 15 tahun diserang kendaraan bermotor. Sekitar $22 \%$ dari total cedera oleh populasi ini. Kasus lain yang terjadi menurut Roberts (2012) menyatakan "The state of Florida has the third highest pedestrian fatality and injury rates in the nation. The mortality rate after pedestrian trauma (3.9 per 100,000) is higher than the national'. Sedangkan di Indonesia dikutip dari CNN Indonesia (2016) menyatakan bahwa Indonesia termasuk tiga besar dunia untuk tingkat kecelakaan. Pada tahun 2014 kecelakaan lalu lintas di Indonesia menyebabkan 29 ribu orang tewas dan 80 ribu terluka mereka berusia 5 sampai 29 tahun.

Perilaku keselamatan bagi anak usia dini sangatlah penting untuk diterapkan. PERMENDIKBUD No 137 Tahun 2014 menyatakan bahwa pada tingkat pencapaian perkembangan anak usia 5-6 tahun yaitu anak sudah mengetahui sesuatu yang membahayakan dirinya dan anak sudah mengetahui tata cara menyebrang. Pendidik selaku fasilitator dalam kegiatan pembelajaran tentunya harus bisa menyampaikan materi untuk memberikan pengetahuan kepada anak tentang perilaku keselamatan bagi pejalan kaki yaitu anak perlu diberikan berupa stimulus pengetahuan tentang perilaku keselamatan anak tetapi proses pembelajaran masih konvensional belum ada inovasi dalam pemberian materi pembelajaran. Maka dari itu dengan adanya pengembangan media pembelajaran diharapkan akan berpengaruh terhadap pengetahuan anak tentang perilaku yang dapat menyelamatkan mereka dalam menghadapi lingkungan yang berbahaya.

Pemanfaatan program dalam pembuatan media pembelajaran kini telah banyak tersedia. Berdasarkan pengamatan peneliti, Firmansyah (2016) menyatakan banyak Software-software yang sering digunakan dalam pembuatan permainan berbasis TIK. Bagi pendidik software yang sering digunakan dalam dunia pendidikan dan praktis dalam penggunaanya yaitu software Powerpoint (Gumawang, 2017).

Powerpoint merupakan program yang umum dimiliki oleh setiap pengguna komputer, sangat mudah dioprasikan oleh pendidik karena biasa digunakan dalam penyampaian materi, bahkan dalam pembuatan permainan bisa dikemas dalam bentuk Powerpoint (Smart, 2012). Menurut Pribadi, dkk. (2011), Anak-anak usia dini sangat menyukai gambar-gambar yang penuh warna dan bentuk yang beragam, Powerpoint memfasilitasi penggunanya dalam mengolah objek gambar, misalnya bentuk garis, teks, dan berbagai gambar lain dan animasi yang disuguhkan dalam Powerpoint guna mendapatkan slide Powerpoint yang cukup menarik untuk pembuatan media pembelajaran. Pada Powerpoint pengguna dapat menggambar objek dengan memanfaatkan tombol yang ada pada menu Toolbar 
Drawing. Powerpoint memberikan keleluasaan bagi pemakainya sehingga permainan dapat disesuaikan dengan tingkatan-tingkatan berpikir peserta didik (Faroqi, 2014).

Observasi telah beberapa kali peneliti lakukan, dan salah satunya penelitian Hernawan, dkk. (2017); Suryono, (2015); Alfian, (2010); dan Darma, (2019) bahwa Powerpoint sudah ada di Sekolah Dasar sebagai media penyampaian materi pembelajaran yang interaktif. Namun pembelajaran di PAUD berbeda dengan SD, Goldenson (1998) menyatakan dalam pembelajaran PAUD adanya bidang pengembangan yang harus tersampaikan melalui kegiatan bermain yang edukatif. Peneliti belum menemukan media pembelajaran berupa materi yang dikemas menjadi permainan berbasis Powerpoint di PAUD.

Berangkat dari permasalahan tersebut, peneliti tertarik untuk mengembangkan media pembelajaran berbasis TIK untuk anak usia 5-6 tahun dengan judul "Media Pembelajaran Berbasis Powerpoint untuk Memfasilitasi Perilaku Keselamatan Anak Usia 5-6 Tahun".

\section{METODOLOGI}

Penelitian ini menggunakan pendekatan kualitatif dengan metode Design Based Research (DBR) yang bertujuan untuk membahas temuan data di lapangan, yang berupa permasalahan disertai solusi berdasarkan rumusan masalah yang telah dibuat. Sesuai dengan tujuan penelitian yaitu merancang, mengembangkan, dan menguji kelayakan suatu produk untuk mengatasi masalah dalam pembelajaran (Lidinillah, 2012). Peneliti akan mengembangkan media pembelajaran berbasis Powerpoint untuk memfasilitasi perilaku keselamatan anak usia 5-6 tahun, oleh karena itu metode DBR cocok diterapkan dalam penelitian, karena penelitian yang dilaksanakan oleh peneliti berhubungan dengan aspekaspek yang sejalan dengan tahapan penelitian dari metode DBR, yakni mengidentifikasi masalah, memberi solusi terhadap masalah (Arikunto, 2006) yakni berupa media pembelajaran berbasis Powerpoint, melakukan pengujian hingga media yang dibuat layak, dan mengevaluasi serta meneliti tentang implikasi yang diberikan oleh media pembelajaran berbasis Powerpoint untuk memfasilitasi perilaku keselamatan anak usia 5-6 tahun (Nursyahidah, 2018).

\section{HASIL DAN PEMBAHASAN}

Penelitian ini dilaksanakan di beberapa PAUD di Kota Tasikmalaya. Sampel yang diambil yaitu kelompok anak usia 5-6 tahun atau bias di sebut Kelompok B (Mulyasa, 2012). Sejalan dengan pendapat Mutiah (2010) masalah yang peneliti temukan adalah media pembelajaran untuk mengoptimalkan sikap sosial anak usia dini masih minim. Menurut Thomson (1996), dan Reynolds, 2015) Perkembangan kognitif menjadi fokus utama ketika proses pembelajaran menggunakan media pembelajaran berbasis komputer. Materi tentang pentingnya keselamatan bagi pejalan kaki belum dikenalkan kepada anak (David, 2018). Solusi yang dirancang oleh peneliti yaitu berupa media pembelajaran berbasis Powerpoint untuk menyampaikan aturan berlalu lintas sebagai pejalan kaki yang mendukung perilaku keselamatan pada anak usia 5 sampai dengan 6 tahun dengan konsep bermain sambil belajar. 
Proses pengembangan produk diawali dengan analisis kurikulum (Sugiyono, 2013). Analisis kurikulum meliputi program pengembangan, kompetensi inti, kompetensi dasar, indikator pencapaian, tujuan pembelajaran, materi, dan media untuk memfasilitasi perilaku keselamatan. Setelah itu, peneliti membuat dasar pengembangan produk, yang merupakan gambaran secara keseluruhan dari media yang akan dibuat. Kemudian peneliti membuat storyboard sebagai desain media yang akan dibuat, berisi gambaran materi, tampilan, serta suara yang akan ditampilkan pada media pembelajaran berbasis Powerpoint.

Tahap rancangan desain produk ini meliputi analisis Kompetensi inti $(\mathrm{KI})$, Kompetensi Dasar (KD), indikator, tujuan pembelajaran, materi, pemaparan tentang komponen media pembelajaran berbasis Powerpoint untuk memfasilitasi perilaku keselamatan anak usia 5-6 tahun.

Tabel 1 Hasil Analisis Program Pengembangan, Kompetensi Inti, Kompetensi Dasar, Indikator Pencapaian, Tujuan Pembelajaran, Materi, dan Media

\begin{tabular}{|c|c|}
\hline $\begin{array}{l}\text { Program } \\
\text { Pengembangan }\end{array}$ & $\begin{array}{l}\text { Perilaku Keselamatan } \\
\text { (Mengetahui situasi yang membahayakan diri, dan } \\
\text { memahami tata cara menyebrang) }\end{array}$ \\
\hline Kompetensi Inti & $\begin{array}{l}\text { KI 2: Sikap Sosial } \\
\text { (Memiliki perilaku hidup sehat, rasa ingin tahu, kreatif dan } \\
\text { estetis, percaya diri, tanggung jawab, jujur, rendah hati dan } \\
\text { santun dalam berinteraksi dengan keluarga, pendidik, dan } \\
\text { teman) }\end{array}$ \\
\hline $\begin{array}{l}\text { Kompetensi } \\
\text { Dasar }\end{array}$ & $\begin{array}{l}\text { (KD 2.2) Memiliki perilaku yang mencerminkan sikap ingin } \\
\text { tahu } \\
\text { (KD 2.3) Memiliki perilaku yang mencerminkan sikap kreatif } \\
\text { (KD 2.5) Memiliki perilaku yang mencerminkan sikap percaya } \\
\text { diri } \\
\text { (KD 2.6) Memiliki perilaku yang mencerminkan sikap taat } \\
\text { terhadap aturan sehari-hari untuk melatih kedisiplinan } \\
\text { (KD 2.7) Memiliki perilaku yang mencerminkan sikap sabar } \\
\text { menunggu mau menunggu giliran, mau mendengar ketika } \\
\text { orang lain berbicara) untuk melatih kedisiplinan } \\
\text { (KD 2.8) Memiliki perilaku yang mencerminkan kemandirian } \\
\text { (KD 2.9) Memiliki perilaku yang mencerminkan sikap peduli } \\
\text { dan mau membantu jika diminta bantuannya } \\
\text { (KD 2.13) Memiliki perilaku yang mencerminkan sikap jujur }\end{array}$ \\
\hline $\begin{array}{l}\text { Indikator } \\
\text { Pencapaian }\end{array}$ & $\begin{array}{l}\text { Indikator pencapaian perkembangan anak untuk } \mathrm{KI} \text { dan } \mathrm{KD} \\
\text { Sikap Sosial tidak dirumuskan secara tersendiri. Pembelajaran } \\
\text { untuk mencapai } \mathrm{KD}-\mathrm{KD} \text { ini dilakukan secara tidak langsung, } \\
\text { tetapi melalui pembelajaran untuk mencapai KD-KD pada K } \\
\text { Pengetahuan dan KI Keterampilan, serta melalui pembiasaan }\end{array}$ \\
\hline
\end{tabular}




\begin{tabular}{|l|l|}
\hline & $\begin{array}{l}\text { dan keteladanan. Dengan kata lain sikap positif anak akan } \\
\text { terbentuk ketika dia memiliki pengetahuan dan mewujudkan } \\
\text { pengetahuan itu dalam bentuk hasil karya dan/atau unjuk } \\
\text { kerja. }\end{array}$ \\
\hline $\begin{array}{l}\text { Tujuan } \\
\text { Pembelajaran }\end{array}$ & $\begin{array}{l}\text { 1. Anak mengetahui situasi yang membahayakan diri } \\
\text { 2. Anak memahami tata cara menyebrang }\end{array}$ \\
\hline Materi & $\begin{array}{l}\text { 1. Etika pejalan kaki } \\
\text { 2. Cara menyebrang yang aman dan selamat }\end{array}$ \\
\hline Media & $\begin{array}{l}\text { Media pembelajaran berbasis Powerpoint untuk } \\
\text { memfasilitasi perilaku keselamatan anak usia 5-6 tahun }\end{array}$ \\
\hline
\end{tabular}

Media pembelajaran berbasis Powerpoint untuk memfasilitasi perilaku keselamatan anak usia 5-6 tahun ini merupakan perpaduan antara gambar, animasi, teks, audio, dan video yang dikemas dan dikembangkan menggunakan aplikasi komputer yaitu Microsoft Powerpoint dengan desain dan tata letak yang menarik menggunakan konsep seperti permainan/games PC yang biasa anak mainkan. Adapun tujuan pengembangan ini yaitu untuk menciptakan varian media berbasis teknologi yang mampu menarik perhatian anak melalui kegiatan bermain yang mengandung edukasi khususnya mengenai perilaku keselamatan anak usia 5-6 tahun

No.

1

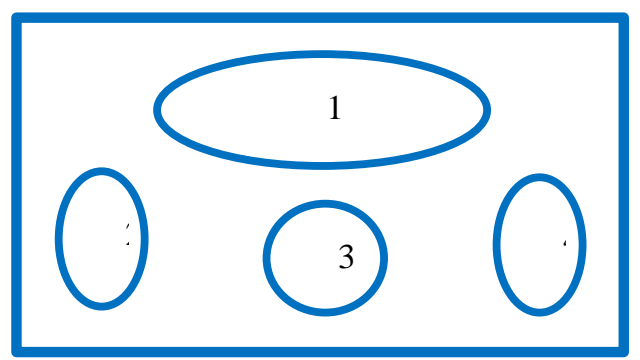

2
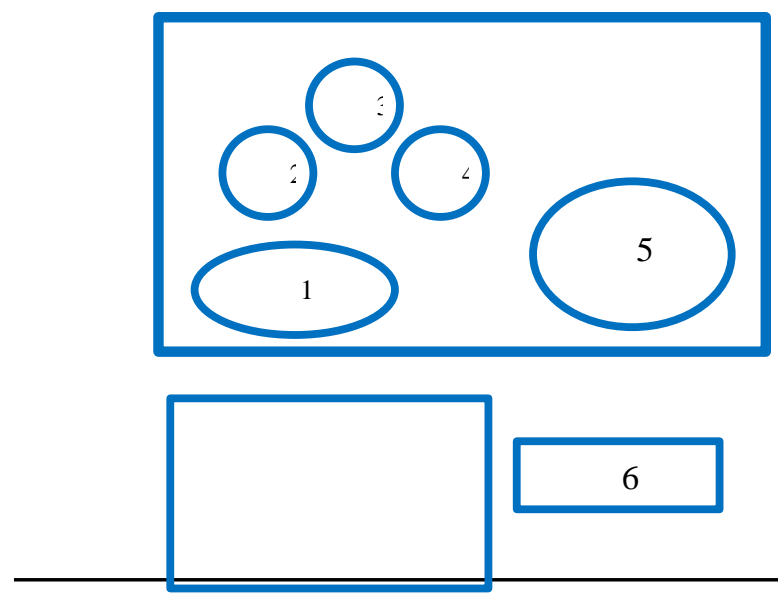
Tampilan
Tabel 2 Storyboard Media Pembelajaran Berbasis Powerpoint Keterangan

\section{Slide Pembuka}

Gambar

No. 1: Nama Media

No. 2: Tokoh Vita

No. 3: Dua tokoh media (Vita dan Vito)

No. 4: Tokoh Vito

Backsound: Nyancat

\section{Menu Utama}

Gambar

No. 1: Nama media

No. 2: Menu belajar

No. 3: Menu petunjuk

No. 4: Menu bermain

No. 5: Tokoh Vita dan Vito

No. 6: Nama Tokoh (Vita dan Vito)

Backsound: Sneaky Snitch 
3

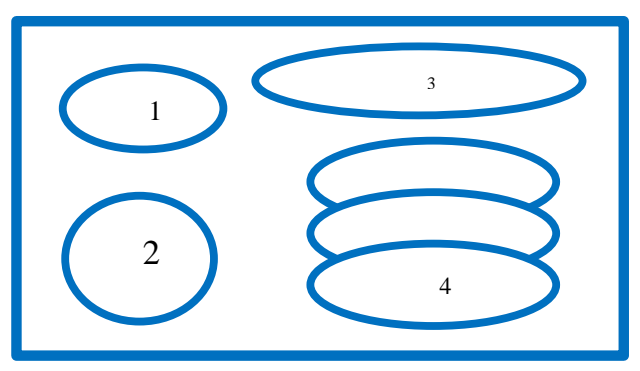

4

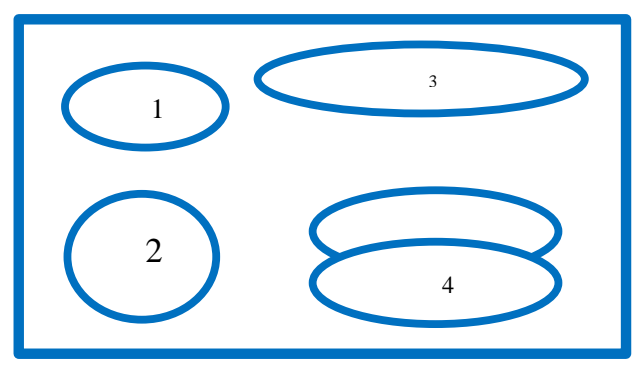

5

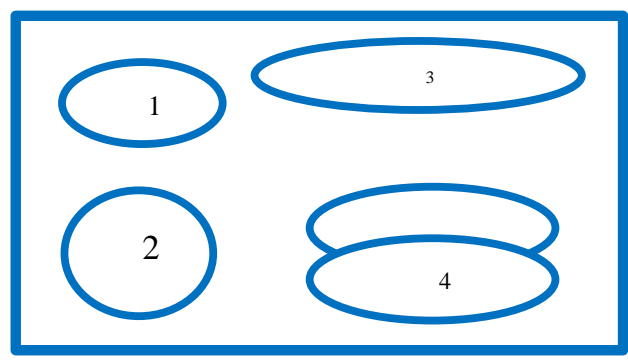

\section{Menu Petunjuk}

Gambar

No. 1: Nama media

No. 2: Tokoh Vita dan Vito

No. 3: Judul sub menu

No. 4: Menu (cara, tentang, home)

Backsound: Sneaky Snitch

Background: Gambar labirin

\section{Menu Belajar}

Gambar

No. 1: Nama media

No. 2: Tokoh Vita dan Vito

No. 3: Judul sub menu

No. 4: Menu (mulai, home)

Backsound: Sneaky Snitch

Background:

Gambar labirin

\section{Menu Bermain}

\section{Gambar}

No. 1: Nama media

No. 2: Tokoh Vita dan Vito

No. 3: Judul sub menu

No. 4: Menu (mulai, home)

Backsound: Sneaky Snitch

Background: Gambar labirin

Revisi produk ini dilakukan berdasarkan diskusi dan saran pada saat validasi oleh ahli. Revisi produk dilakukan agar pengembangan media pembelajaran berbasis Powerpoint untuk memfasilitasi perilaku keselamatan pada anak usia 5-6 tahun menjadi layak digunakan saat proses uji coba pada anak usia 5-6 tahun. 


\section{Tabel 3 Revisi Produk Media Pembelajaran Berbasis Powerpoint}

No.

\section{Saran validator}

Tokoh Tikus dalam media pembelajaran sebaiknya diganti menjadi tokoh anak karena konten media berisi tentang perilaku

1. keselamatan pada anak jadi anak yang menjadi tokoh utama dalam media. Alangkah lebih baik lagi apabila gambar tersebut adalah hasil karya sendiri.

Sisipkan background dengan desain yang menjadi ciri khas media

2. dan penggunaan bahasa tolong perbaiki sesuaikan dengan teori permainan untuk anak usia dini.

Sesuaikan karakter tokoh

3. dengan isi tujuan dari media.

Tolong perbaiki menu utama dengan pilihan tidak terbatas hanya permainan saja karena nama media adalah "media

4. pembelajaran" maka alangkah lebih baik lagi jika di tambah dengan materi tentang perilaku keselamatan yang sesuai dengan anak 5-6 tahun.

Dalam menu bermain alangkah lebih baik lagi jika slide langsung

5. terhubung ke level dengan pilihan mulai, dan home untuk kembali ke menu utama.

\section{Produk sebelum revisi}

\section{Produk sesudah revisi}
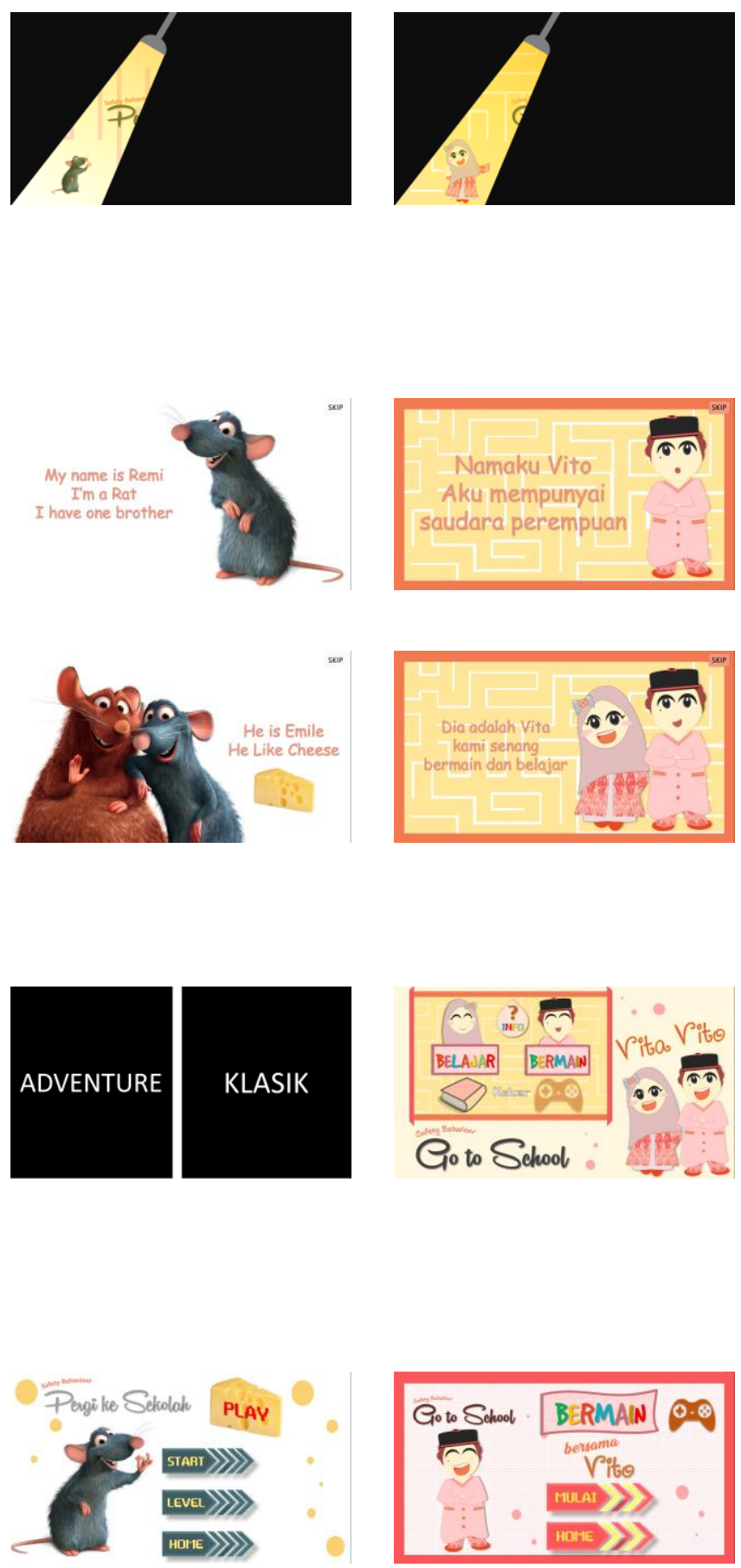
Dalam menu info

6. sebaiknya memunculkan dua tokoh sebagai icon.

Tampilan awal sebelum masuk kepada permainan sebaiknya ada petunjuk

7. perintah untuk menekan tombol navigasi. Desain dan tata letak tolong diperbaiki tidak terlepas
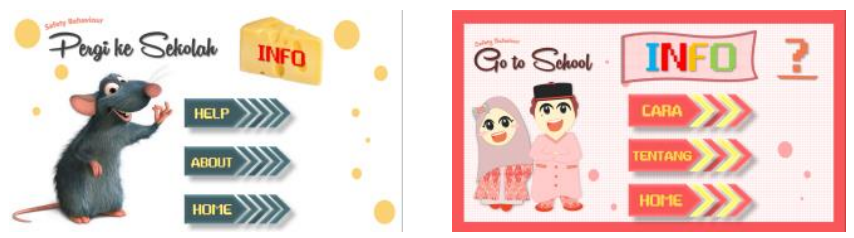
dari ciri khas media.

Konsep dari permainan disesuaikan dengan tokoh yang akan diganti

8. termasuk menyesuaikan konten lainnya yang akan mempengaruhi judul
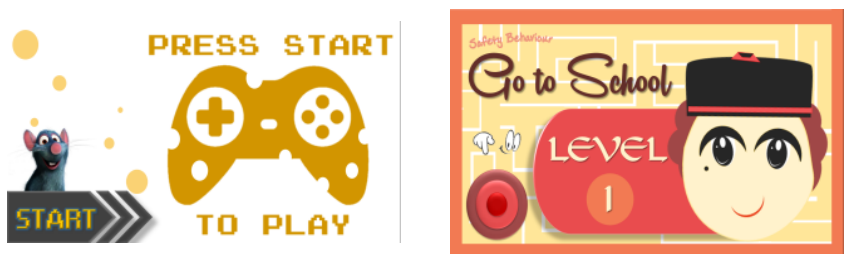
media.
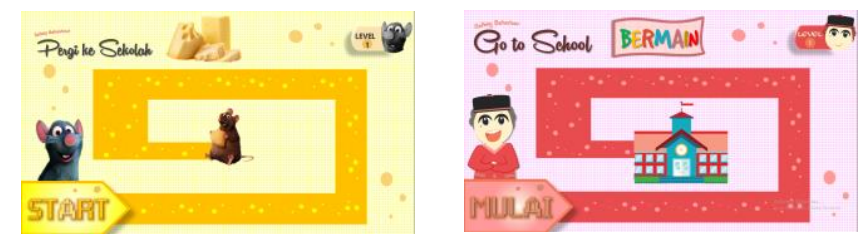

Setelah melakukan validasi produk, tahap selanjutnya yang dilakukan peneliti yaitu uji coba produk dan juga validitas eksternal. Uji coba ini dilakukan sebanyak dua kali di sekolah yang berbeda, yakni sekolah dengan middle ranking dan high ranking. Uji coba produk ini bertujuan untuk mengetahui kelayakan produk media pembelajaran berbasis Powerpoint untuk memfasilitasi perilaku keselamatan anak usia 5-6 tahun dalam pembelajaran di lingkungan kelas kelompok B.

\section{Tabel 4 Efektifitas Hasil belajar Anak terhadap Media Pembelajaran Berbasis Powerpoint}

\begin{tabular}{|c|l|r|c|c|c|}
\hline \multirow{2}{*}{ No. Indikator } & \multicolumn{4}{|c|}{ Ya } & \multicolumn{2}{|c|}{ Tidak } \\
\cline { 3 - 6 } & \multicolumn{1}{|c|}{$\begin{array}{c}\text { Yalaian } \\
\text { se }\end{array}$} & $\begin{array}{c}\text { Jm } \\
\text { I }\end{array}$ & $\begin{array}{c}\text { Persentas } \\
\text { e }\end{array}$ \\
\hline \multirow{2}{*}{1} & $\begin{array}{l}\text { Menambah pengetahuan tentang } \\
\text { perilaku keselamatan anak }\end{array}$ & 14 & $73,7 \%$ & 5 & $26,3 \%$ \\
\cline { 2 - 6 } & $\begin{array}{l}\text { Kegiatan pembelajaran menjadi } \\
\text { menyenangkan bagi anak }\end{array}$ & 16 & $84,2 \%$ & 3 & $15,8 \%$ \\
\cline { 2 - 6 } & Motivasi belajar anak meningkat & 15 & $78,9 \%$ & 4 & $21,1 \%$ \\
\cline { 2 - 6 } & Materi mudah dipahami oleh anak & 15 & $78,9 \%$ & 4 & $21,1 \%$ \\
\hline \multirow{2}{*}{2} & $\begin{array}{l}\text { Teks yang ditampilkan terbaca } \\
\text { dengan jelas oleh anak }\end{array}$ & 19 & $100 \%$ & 0 & $0 \%$ \\
\cline { 2 - 6 } & $\begin{array}{l}\text { Gambar yang ditampilkan terlihat } \\
\text { dengan jelas oleh anak }\end{array}$ & 19 & $100 \%$ & 0 & $0 \%$ \\
\hline
\end{tabular}




\begin{tabular}{|c|l|r|r|r|c|}
\hline & $\begin{array}{l}\text { Animasi yang ditampilkan menarik } \\
\text { perhatian anak }\end{array}$ & 19 & $100 \%$ & 0 & $0 \%$ \\
\cline { 2 - 5 } & $\begin{array}{l}\text { Suara latar musik terdengar dengan } \\
\text { jelas oleh anak }\end{array}$ & 19 & $100 \%$ & 0 & $0 \%$ \\
\hline $\begin{array}{l}\text { Suara tokoh terdengar dengan jelas } \\
\text { oleh anak }\end{array}$ & 17 & $89,5 \%$ & 2 & $10,5 \%$ \\
\hline \multirow{2}{*}{3} & $\begin{array}{l}\text { Menggunakan Bahasa Indonesia } \\
\text { dan Bahasa Inggris yang baik dan } \\
\text { benar }\end{array}$ & 19 & $100 \%$ & 0 & $0 \%$ \\
\cline { 2 - 6 } & $\begin{array}{l}\text { Bahasa yang digunakan mudah } \\
\text { dimengerti dan dipahami oleh anak }\end{array}$ & 17 & $89,5 \%$ & 2 & $10,5 \%$ \\
\hline \multirow{2}{*}{4} & $\begin{array}{l}\text { Navigasi mudah digunakan oleh } \\
\text { anak }\end{array}$ & 19 & $100 \%$ & 0 & $0 \%$ \\
\hline $\begin{array}{l}\text { Petunjuk penggunaan mudah } \\
\text { dipahami oleh anak }\end{array}$ & 19 & $100 \%$ & 0 & $0 \%$ \\
\cline { 2 - 6 } Rata-rata Persentase & \multicolumn{2}{|c|}{$91,2 \%$} & & $8,8 \%$ \\
\hline
\end{tabular}

Tabel 5 Efektifitas Hasil belajar Anak terhadap Media Pembelajaran Berbasis Powerpoint Setelah Revisi

\begin{tabular}{|c|c|c|c|c|c|}
\hline \multirow{3}{*}{ No. } & \multirow{3}{*}{ Indikator } & \multicolumn{4}{|c|}{ Penilaian } \\
\hline & & \multicolumn{2}{|r|}{$\mathrm{Ya}$} & \multicolumn{2}{|c|}{ Tidak } \\
\hline & & $\underset{\mathrm{J}}{\mathrm{Jm}}$ & $\begin{array}{l}\text { Persenta } \\
\text { se }\end{array}$ & $\mathrm{Jm}$ & $\begin{array}{l}\text { Persenta } \\
\text { se }\end{array}$ \\
\hline \multirow{4}{*}{1} & $\begin{array}{l}\text { Menambah pengetahuan } \\
\text { tentang perilaku keselamatan } \\
\text { anak }\end{array}$ & 13 & $81,3 \%$ & 3 & $18,7 \%$ \\
\hline & $\begin{array}{l}\text { Kegiatan pembelajaran menjadi } \\
\text { menyenangkan bagi anak }\end{array}$ & 13 & $81,3 \%$ & 3 & $18,7 \%$ \\
\hline & Motivasi belajar anak meningkat & 14 & $87,5 \%$ & 2 & $12,5 \%$ \\
\hline & $\begin{array}{l}\text { Materi mudah dipahami oleh } \\
\text { anak }\end{array}$ & 12 & $76,9 \%$ & 4 & $23,1 \%$ \\
\hline \multirow{5}{*}{2} & $\begin{array}{l}\text { Teks yang ditampilkan terbaca } \\
\text { dengan jelas oleh anak }\end{array}$ & 16 & $100 \%$ & 0 & $0 \%$ \\
\hline & $\begin{array}{l}\text { Gambar yang ditampilkan } \\
\text { terlihat dengan jelas oleh anak }\end{array}$ & 16 & $100 \%$ & 0 & $0 \%$ \\
\hline & $\begin{array}{l}\text { Animasi yang ditampilkan } \\
\text { menarik perhatian anak }\end{array}$ & 16 & $100 \%$ & 0 & $0 \%$ \\
\hline & $\begin{array}{l}\text { Suara latar musik terdengar } \\
\text { dengan jelas oleh anak }\end{array}$ & 16 & $100 \%$ & 0 & $0 \%$ \\
\hline & $\begin{array}{l}\text { Suara tokoh terdengar dengan } \\
\text { jelas oleh anak }\end{array}$ & 14 & $87,5 \%$ & 2 & $12,5 \%$ \\
\hline 3 & $\begin{array}{l}\text { Menggunakan Bahasa } \\
\text { Indonesia dan Bahasa Inggris } \\
\text { yang baik dan benar }\end{array}$ & 16 & $100 \%$ & 0 & $0 \%$ \\
\hline
\end{tabular}




\begin{tabular}{|c|l|c|c|c|c|}
\hline & $\begin{array}{l}\text { Bahasa yang digunakan mudah } \\
\text { dimengerti dan dipahami oleh } \\
\text { anak }\end{array}$ & 14 & $87,5 \%$ & 2 & $12,5 \%$ \\
\hline \multirow{2}{*}{4} & $\begin{array}{l}\text { Navigasi mudah digunakan oleh } \\
\text { anak }\end{array}$ & 16 & $100 \%$ & 0 & $0 \%$ \\
\cline { 2 - 5 } & $\begin{array}{l}\text { Petunjuk penggunaan mudah } \\
\text { dipahami oleh anak }\end{array}$ & 16 & $100 \%$ & 0 & $0 \%$ \\
\cline { 2 - 5 } & Rata-rata Persentase & \multicolumn{2}{|c|}{$93,2 \%$} & $6,8 \%$ \\
\hline
\end{tabular}

Berdasarkan efektifitas hasil belajar anak pada tabel 4 \& 5 diatas menyatakan bahwa hasil belajar anak-anak kelompok B terhadap produk pengembangan media pembelajaran berbasis Powerpoint untuk memfasilitasi perilaku keselamatan anak usia 5-6 tahun sangat baik dan meningkat persentasenya. Hal ini sesuai dengan rata-rata presentase hasil akhir yaitu dari $91,2 \%$ menjadi $93,2 \%$.

Selain efektifitas hasil belajar anak, peneliti memperoleh data menggunakan lembar penilaian media untuk mengetahui penilaian dari guru terhadap media pembelajaran berbasis Powerpoint untuk memfasilitasi perilaku keselamatan anak usia 5-6 tahun. Pendapat guru kelompok B yaitu media pembelajaran ini sangat inovatif, anak-anak sangat senang dan antusias dengan hal yang baru dalam kegiatan proses belajar mengajar, materi tentang perilaku keselamatan anak usia 5-6 tahun tersampaikan dengan tepat dan menyenangkan, diharapkan media pembelajaran ini bisa dimiliki orangtua untuk pembelajaran di rumah untuk mempermudah penggunaan media pembelajaran berbasis Powerpoint untuk memfasilitasi perilaku keselamatan anak usia 5-6 tahun ini dilengkapi dengan buku panduan. Guru berharap agar pengembangan media berbasis teknologi menghasilkan beberapa produk yang bervariasi dalam memfasilitasi proses pembelajaran berbasis teknologi dengan desain yang kreatif dan inovatif.

Tahap terakhir pada penelitian ini yaitu refleksi dari pengembangan produk, yakni menghasilkan produk akhir berupa CD, dan buku panduan pengembangan media pembelajaran berbasis Powerpoint untuk memfasilitasi perilaku keselamatan anak usia 5-6 tahun. Produk ini memuat materi tentang perilaku keselamatan bagi pejalan kaki yang dikaitkan dengan aturan berlalu lintas yang baik dan benar agar selamat. Produk ini berisi materi tentang bagaimana sikap kita saat berada dijalan raya, tata cara menyebrang agar aman dan selamat, dan permainan labirin sebagai variasi dari media pembelajaran. Hal-hal tersebut mampu meningkatkan perhatian dan motivasi belajar anak selama proses pembelajaran (Jonas, 2010).

Jika fasilitas TIK memadai maka media pembelajaran berbasis Powerpoint untuk memfasilitasi perilaku keselamatan anak usia 5-6 tahun ini dapat digunakan oleh guru pada pembelajaran di kelas, dan juga bisa digunakan orangtua untuk digunakan di rumah. Pada saat penggunaan media pembelajaran berbasis Powerpoint ini, anak kelompok B atau anak usia 5-6 tahun lebih baik didampingi orang dewasa agar mendapat bimbingan yang tepat dan 
mendapatkan keterampilan, pengetahuan, serta perkembangan sikap (Vygotsky, 1978; \& Sudrajat, 2018).

Hasil akhir dari tahap pengembangan media pembelajaran berbasis Powerpoint untuk memfasilitasi perilaku keselamatan anak usia 5-6 tahun ini menyebarkan produk secara terbatas yaitu di beberapa PAUD Kota Tasikmalaya sebagai alternatif pilihan media pembelajaran perilaku keselamatan anak usia 56 tahun. Berikut ini adalah kelebihan dan kekurangan media pembelajaran berbasis Powerpoint untuk memfasilitasi perilaku keselamatan anak usia 5-6 tahun:

\section{Kelebihan}

1) Media dirancang berdasarkan teori para ahli dari jurnal internasional dan permendikbud 137 tahun 2014.

2) Media dikemas dan dikembangkan menggunakan aplikasi komputer yaitu Microsoft Powerpoint yang merupakan aplikasi yang umum digunakan dalam dunia pendidikan.

3) Media pembelajaran yang inovatif dan kreatif dengan konsep berbasis teknologi dibuat interaktif dengan aplikasi yang biasa digunakan untuk presentasi.

4) Konsep media yang interaktif dan menyenangkan membuat antusias anak dalam mengikuti proses pembelajaran di kelas.

5) Desain dan tata letak yang menarik dengan menggunakan konsep seperti permainan/games PC yang biasa anak mainkan sesuai dengan dunia anak yang senang bermain.

6) Bersifat multifungsi karena materi dan permainan dikemas dalam satu perangkat sehingga proses pembelajaran menjadi lebih bervariatif dan lengkap dengan konsep bermain sambil belajar.

7) Mampu digunakan di kelas atau di rumah dengan bimbingan orang dewasa.

8) Pengemasan media pembelajaran berbasis Powerpoint untuk memfasilitasi perilaku keselamatan anak usia 5-6 tahun dalam bentuk CD disertai dengan buku panduan yang di desain unik dan menarik.

\section{Kekurangan}

1) Media hanya bisa digunakan $P C /$ Laptop

2) Keterbatasan Fasilitas TIK di sekolah

3) Keterampilan guru dalam mengoprasikan alat TIK

4) Materi terbatas karena hanya membahas tentang perilaku keselamatan bagi pejalan kaki untuk anak usia 5-6 tahun

Proses pembuatan media membutuhkan waktu yang cukup lama melalui proses penelitian sehingga kesabaran dan keuletan adalah kunci utama keberhasilan pembuatan media.

\section{SIMPULAN}

Pada penelitian ini menunjukkan bahwa peranan media pembelajaran sangat penting. Media pembelajaran yang memiliki fungsi sebagai alat penyampai pesan kepada anak dari guru yang akan menambah proses pembelajaran menjadi lebih efektif dan kondusif, serta anak lebih menyerap materi secara komprehensif. 
Media pembelajaran berbasis teknologi memiliki pengaruh besar terhadap motivasi belajar dan hasil belajar anak, karena media pembelajaran berbasis teknologi merupakan media pembelajaran yang efektif dan akan meningkatkan motivasi belajar anak, sehingga anak senang mengikuti pembelajaran dan berpengaruh terhadap hasil belajar anak yang berkualitas.

Media pembelajaran berbasis Powerpoint untuk memfasilitasi perilaku keselamatan anak usia 5-6 tahun dinyatakan layak dan dapat digunakan karena memberikan implikasi sebagai berikut:

1) Sebagai media pembelajaran yang dirancang khusus untuk memfasilitasi perilaku keselamatan anak usia 5-6 tahun.

2) Media dilengkapi dengan perpaduan gambar, animasi, teks, video,dan audio dirancang menggunakan aplikasi Powerpoint dengan konsep permainan.

3) Dapat digunakan sebagai bahan ajar mandiri maupun secara klasikal dalam pembelajaran untuk memfasilitasi perilaku keselamatan anak usia 5-6 tahun.

Berdasarkan temuan dan pembahasan yang diperoleh dari penelitian ini, didapatkan beberapa rekomendasi yang diberikan dan dipaparkan sebagai berikut:

1) Bagi pengguna media pembelajaran berbasis Powerpoint untuk memfasilitasi perilaku keselamatan anak usia 5-6 tahun diharapkan dapat menggunakan setiap komponen media secara optimal dan dapat mengemasnya secara menarik, inovatif, dan kreatif, seperti menggunakan konsep permainan yang bisa membangkitkan motivasi anak dalam belajar.

2) Penggunaan media pembelajaran berbasis Powerpoint untuk memfasilitasi perilaku keselamatan anak usia 5-6 tahun akan berjalan optimal apabila guru dapat mengondisikan anak dalam menggunakan media, baik secara mandiri maupun klasikal.

3) Pada dasarnya tidak ada hal yang sempurna termasuk media pembelajaran, hal yang ada hanya media pembelajaran yang sesuai dengan tema pada proses pembelajaran. Sehingga dalam penggunaan media yang telah dirancang oleh peneliti dapat dikembangkan kembali oleh guru, mahasiswa, maupun pihak lain yang berkenan. Dapat dilakukan penelitian lebih lanjut dalam hal pengaruh keefektifan media maupun menyangkut perangkat bahan ajar lainnya. Dapat pula diuji cobakan pada lokasi lain serta dimodifikasi lebih baik lagi.

\section{DAFTAR PUSTAKA}

Alfian. (2010). Pengembangan Game Edukasi Interaktif pada Mata Pelajaran Komposisi Foto Digital. Ejurnal. Vol 1 No 2: Universitas Negeri Surabaya

Arikunto. (2006). Prosedur Penelitian, Suatu Pendekatan Praktik. Jakarta: Rineka Cipta.

CNN Indonesia. (2016). Selamatkan Anak Dari Lalu Lintas. Artikel. Jakarta

Darma. (2019). Perancangan Animasi Interaktif. Ejurnal: TK Pedindin Jakarta Utara

David, K. (2018). Distinguishing Gains in Knowledge from Gains in Safe Behavior. Ejournal. New York: doi: 10.1007/s10935-014-0341-8 
Faroqi, A. (2014). Aplikasi Multimedia Interaktif Pembelajaran Membaca, Menulis,Berhitung (Calistung). Jurnal Sains dan Teknologi: 8, 2.

Firmansyah. (2016). TIK Beserta Pengembangan. Artikel: Nasabah media

Goldenson. (1998). Interactive Multimedia for Promoting Physical Activity (IMPACT) in Children. Obesity Research. 13, 4. 762-771.

Gumawang, A. (2007). Manfaat Powerpoint Dalam Presentasi Makalah. Ejurnal. Vol 6 No 1: Saintikom

Hernawan, dkk. (2007). Media pembelajaran Sekolah Dasar. Bandung: UPI PRESS.

(2010). Brand Operation The Official MIM Academy Course Book. Jakarta: Erlangga.

Jonas. (2010). A School-Based Pedestrian Safety Intervention Program. Ejurnal. Francis: Institute at the Ryder Trauma Center.

Latif, dkk. (2013). Orientasi Baru Pendidikan Anak Usia Dini. Teori Dan Aplikasi. Jakarta: Prenada Media.

Lidinillah. (2012). Educational Design Research: a Theoretical Framework for Action. Tasikmalaya: Universitas Pendidikan Indonesia Kampus Tasikmalaya.

Marlon, G. (2017). WalkSafe A School-Based Pedestrian Safety Intervention Program. Ejournal. Florida: doi: 10.1080/15389580490510507

Morrongiello. (2015). Study on Pedestrian Crossing Behavior at Signalized Intersections. Ejournal: Bombay

Mulyasa. (2012). Managemen PAUD. Bandung: Rosda Karya

Mutiah. (2010). Psikologi Bermain Anak Usia Dini. Jakarta: Prenada Media Group.

NCSA. (2010). Publikasi Pencegahan Cedera Lalu Lintas. Articel. North Carolina

Nursyahidah, F. (2018). (t.t). Research and development vs depelopment research.Jurnal, hlm. 1-27. Diakses dari https: //faridanursyahidah.wordpress.com/author/faridanursyahidah/page/2/.

Peraturan Pemerintah Pendidikan dan Kebudayaan No 137 tahun 2014 tentang Standar Nasional Pendidikan Anak Usia Dini

Pribadi, dkk. (2012). Komputer dalam Kegiatan Pengembangan Anak Usia Dini. Jakarta: Universitas Terbuka.

Reynolds, K (2015). Helping Children Learn Mathematics. Ejurnal. Boston: Allyn and Bacon.

Roberts, I. (2012). Safety Education Of Pedestrians For Injury Prevention. Ejournal: University of Miami School of Medicine

Landasan Konseptual Media Pembelajaran. Workshop Media Pembelajaran bagi Guru-guru SMAN Banjar Angkan: Bali

Sudrajat. (2018). Proses Perkembangan Anak. Artikel: Definisimu

Sugiyono. (2013). Metode Penelitian Pendidikan. Bandung: Alfabeta.

Sujiono. (2013). Konsep Dasar Pendidikan Anak Usia Dini. Jakarta: PT Indeks.

Suryono. (2015). Optimalisasi Microsoft Office Powerpoint 2016 Dalam Pembuatan Media Interaktif Penggandaan Dokumen Untuk Program Keahlian Administrasi Perkantoran Sekolah Menengah Kejuruan Negeri Indonesian Jurnal on Computer Science. Volume 10 No 4. 
Smart, A. (2012). Manfaat Powerpoint. Ejurnal. Yogyakarta: Gava Media

Thomson. (1996). Cognitive Development and The Acquisition of Language. New York: Academica Press.

Vygotsky. (1978). Development for Childrend. Jurnal, hlm. 1-27. Diakses dari https:

//faridanursyahidah.wordpress.com/author/faridanursyahidah/page/2/.

Undang-undang No 20. (2003), Tentang Sistem pendidikan nasional. Jakarta: Republik Indonesia. 